\title{
Oversizing Penile Prosthesis Length as per the Erect Length by Intra-Cavernosal Injection of Vasoactive Material
}

\section{Original Article}

\author{
Osama Shaeer, Kamal Shaeer, Islam Fathy Soliman AbdelRahman
}

Department of Andrology, Kasr El Aini Faculty of Medicine, Cairo University, Cairo, Egypt

\begin{abstract}
Introduction: Penile prosthesis implantation (PPI) is becoming increasingly popular for treatment of erectile dysfunction that will not respond to medical treatment. However, reasons for dissatisfaction with PPI, decreased penile size was among the reasons stated by the patients, quoting "it got small, the prosthesis is short, it does not have enough thickness, it does not get to the front".

Aim of Study: To evaluate patient and partner's impression of penile length when implanting penile prosthesis with cylinder length determined in the erect state, compared to regular implantation as per the flaccid stretched length.

Patients and Methods: A 3-piece girth expanding penile prosthesis was implanted in 38 patients: 16 patients with cylinder length sized in the erect state, induced by intra-cavernosal injection of vasoactive material (ICI) (study group), compared to regular implantation as per the flaccid stretched length (control group; $n=22$ ). Patients in the study group were educated as to signs of pending perforation and instructed to seek urgent consultation if such signs set in. Patients were followed up for 20-24 months. Complications and patients/partner impression of post-operative erect length compared to their recall of erect length before ED had set in.

Results: In the study group, $6.2 \%$ of patients and $12.5 \%$ of partners reported shorter length, compared to $81.9 \%$ of patients and $95.5 \%$ of partners in the control group $(p<0.001)$. One case $(6.3 \%)$ in the study group showed signs of pending anterior perforation by the ninth month post-operatively. Re-operation was performed, removing a $1 \mathrm{~cm}$ rear tip extender from each cylinder.

Conclusion: Implantation of an inflatable penile prosthesis with cylinder length determined in the erect state is both safe and effective in preserving impression of penile length, provided the benefits outweigh the slightly higher risk of anterior perforation, and that pending perforation is detected early enough in which case the implant can be shortened.
\end{abstract}

Key Words: Intra-cavernosal injection, oversizing, penile implant, penile length, penile prosthesis

Received: 18 May 2017, Accepted: 22 December 2017

Corresponding Author: Osama Shaeer, Faculty of Medicne, Cairo University, Cairo, Egypt, Tel.: +201006600606, E-mail: Osamashaeer@gmail.com.

ISSN: 2537-0014

\section{INTRODUCTION}

High satisfaction rates have been reported for penile prosthesis implantation (PPI) for treating erectile dysfunction (ED), particularly with inflatable implants. In one study, $79 \%$ of patients and $74 \%$ of their partners reported satisfactory intercourse ${ }^{[1]}$. Seventy nine percent satisfaction rate was also reported by Carvalheira et al. ${ }^{[2]}$. With three-piece inflatable implants, patient satisfaction was $88.9 \%$ and partner satisfaction was $94.4 \%{ }^{[3]}$, while with two-piece inflatable implants, satisfaction was good in $42 \%$ of patients, quite good in $33,3 \%$, quite bad in $2,4 \%$ and very bad in $7,1 \%{ }^{[4]}$.

Decreased penile size is among the reasons for dissatisfaction following $\mathrm{PPI}^{[2]}$. Shortening -or impression thereof- may be due to the customary sizing method where determination of the length of the implant is as per the flaccid stretched state and not the erect. In patients with peripheral neuropathy, sizing should be even more conservative. Further dissatisfaction is noted in patients with a risk factor for shortening such as those with Peyronie's disease ${ }^{[5]}$, post-radical prostatectomy ${ }^{[6]}$, post-neglected priapism ${ }^{[7]}$, and in patients with a concealed penis.

\section{AIM OF STUDY}

The current study evaluates penile prosthesis sizing as per the erect state as induced by intra-cavernosal injection of vasoactive material, compared to regular implantation as per the flaccid stretched state, evaluated in terms of patient and partner's impression of penile length. 


\section{PATIENTS AND METHODS}

Thirty-eight patients with erectile dysfunction refractory to medical treatment were included in this study, all undergoing surgery for implantation of a 3-piece girth expanding penile prosthesis (Titan, Coloplast Corp Minneapolis - USA). Patients were divided into two groups: 16 patients with the cylinder length measured in the erect state, induced by intra-cavernosal injection of vasoactive material (ICI) (study group), compared to regular implantation as per the flaccid stretched length (control group; $n=22$ ). Patients with risk factor for shortening such as Peyronie's disease, previous penile surgery or postradical prostatectomy were excluded. Diabetic patients were also excluded in this preliminary investigation, for they have a higher liability for penile hyposensitivity and anterior perforation. Ethical approval and informed written consents were obtained.

Implantation was performed by a single surgeon, under general anesthesia, through a penoscrotal incision. For the study group, ICI of $1 \mathrm{~mL}$ Trimix $(150 \mathrm{mg} \backslash$ papaverine, $50 \mu \mathrm{g}$ prostaglandin $\mathrm{E} 1$ and $5 \mathrm{mg}$ phentolamine in $5 \mathrm{~mL}$ solution) was performed before corporotomy, supplemented by saline injection through a butterfly canula, to induce full erection. Full erection was maintained for 5 minutes to gain full expansion of the corporal bodies. Corporotomy and subsequent sizing were performed and the prosthesis implanted. The implant was left fully inflated for 14 days (we hypothesize that this will adapt the corporal bodies to the intended erect length), with daily follow up for signs of impending anterior erosion such as skin discoloration, whether in office visits or online. Patients were educated to identify signs of impending erosion and instructed to seek urgent consultation if such signs set in. In the control group, the prosthesis was implanted as usual with cylinder length determined as per the flaccid stretched length, without ICI.

Patients were followed up for 24 months as regards complications particularly impending anterior erosion, in which case they would be re-operated upon for removing one or more rear-tip extenders. This was included in the patient consent before surgery.

Patient and partner impression of post-operative erect length was evaluated, compared to their recall of erect length before ED had set in, using the following question:

How do you find the length of the penis after surgery compared to before ED had set in?

\section{-Longer}

-The same

-Shorter.

Statistical analysis was performed using Microsoft Excel 2010 and SPSS version 19. Data were represented as mean and standard deviation as well as percentage where appropriate. Comparison of categorical values was performed using Chi square test.

\section{RESULTS}

Patient demographics and cause for ED are listed in Table 1 . In the study group, $15 / 16$ patients $(93.8 \%)$ and $14 / 16$ partners $(87.5 \%)$ reported the post-implantation length (with the device fully inflated) to be "the same as" erect length as they recall it before ED had set in. Consequently, $6.2 \%$ of patients and $12.5 \%$ of partners in the study group reported shorter length. This is in contrast to the control group where $18 / 22$ patients $(81.9 \%$ ) and $21 / 22$ partners $(95.5 \%)$ reported a shorter post-implantation erect length compared to before ED had set in $(p<0.001)$.

Table 1: Patient demographics.

\begin{tabular}{lccc}
\hline \multicolumn{2}{c}{ Study Group } & \multicolumn{2}{c}{ Control Group } \\
\hline Age & $47 \pm 5.8$ & $49 \pm 7.1$ & $p=0.42$ \\
Venogenic & $84 \%$ & $78 \%$ & \\
ED & & & \\
Arteriogenic & $16 \%$ & $22 \%$ & \\
ED & & & \\
\hline
\end{tabular}

Pain was more pronounced in the study group for the first 2 weeks; a subjective impression of the authors. Two months post-operatively, pain was comparable in both the study and control groups. One case $(6.3 \%)$ in the study group showed signs of impending anterior erosion by the ninth month post-operatively. Re-operation was performed, removing a one $\mathrm{cm}$ rear tip extender on either sides.

\section{DISCUSSION}

Length of the penis has a known influence on man's ego and sexuality, and a debatable influence on partner's satisfaction $^{[8]}$. Dissatisfaction with penile length has been reported as a risk factor for erectile dysfunction ${ }^{[9]}$, and is important for sexual fulfillment in a subset of females ${ }^{[10]}$

Several studies have demonstrated a decrease in length following PPI. One study reported shortening in the range of $0.74 \pm 0.15 \mathrm{~cm}^{[11]}$. Another study reported that length was $9.5 \%$ shorter postoperatively ${ }^{[12]}$. Despite the relatively minor decrease in post-implantation length, the complaint of a shorter penis following PPI remains prevalent, with $72 \%$ of patients reporting a decrease in penile length $^{[13]}$. In the absence of risk factors for penile shortening, this decrease in length is primarily due to implantation in the flaccid stretched state rather than in the erect state, in order to avoid oversizing that may lead to anterior perforation or persistent pain.

Pre and post-operative counseling can help alleviate patient dissatisfaction with penile size following PPI. Further measures include implantation of length expanding implants, traction to penis before implantation ${ }^{[9,10]}$, suspensory ligament release with or 
without V-Y skin plasty ${ }^{[14-17]}$, suprapubic lipectomy ${ }^{[14]}$, or a combination of various augmentation techniques post-implantation ${ }^{[15]}$. Ventral phalloplasty may also enhance satisfaction by removing the penoscrotal web, revealing the ventral aspect of the penis ${ }^{[16,17]}$. Dorsal phalloplasty (DP) is a minimally invasive same-session adjuvant technique to PPI, revealing the dorsal aspect of the base of the penis ${ }^{[18]}$. However, the fore mentioned measures do not address the root cause for shortening which is implantation as per the flaccid stretched length and not the erect length.

In our experience, implantation of an inflatable penile prosthesis as per the erect length was safe, and effective in maintaining impression of length. In defense of safety of this concept is that patients with neglected ischemic priapism have the implant length determined as per the erect length, without necessarily suffering anterior perforation or excessive pain. Also, length expanding implants have proven safe. Nevertheless, patients should be warned that the possibility of anterior perforation may -theoretically speaking- be higher $(6.3 \%$ in the current series), requiring follow up and education as to early detection of the signs thereof, such that the prosthesis is shortened if required. Therefore, the need for implantation in the erect state should outweigh this risk in the patient's perception and priorities. This could be the case with patients where the flaccid penis is retractile rather than pendulous.

We do not recommend this approach for semi-rigid implants and for those with liability for perforation such as patients with paraplegia or severe sensory neuropathy. Upon selecting the number of rear tip extenders, we advise to use at least two extenders with one of them being $1 \mathrm{~cm}$ long, such that it could be removed if needed, if signs of pending anterior perforation set-in. Among the limitations of this study is that length is evaluated subjectively, compared to pre-ED length, by memory recall.

\section{CONCLUSION}

Implantation of an inflatable penile prosthesis with cylinder length determined in the erect state is both safe and effective in preserving impression of penile length, provided the benefits outweigh the slightly higher risk of anterior perforation. Impending erosion must be watched out for, and detected early enough, in which case the implant can be shortened.

\section{CONFLICT OF INTERST}

There are no conflicts of Interest.

\section{REFERENCES}

1. Lledo-Garcia E, Jara-Rascon J, Moncada Iribarren I, Pinero-Sanchez J, Aragon-Chamizo
J, Hernandez-Fernandez C. Penile Prosthesis First and Replacement Surgeries: Analysis of Patient and Partner Satisfaction. J Sex Med. 2015 Jul;12(7):1646-53.

2. Carvalheira A, Santana R, Pereira NM. Why Are Men Satisfied or Dissatisfied with Penile Implants? A Mixed Method Study on Satisfaction with Penile Prosthesis Implantation. J Sex Med. 2015 Dec;12(12):2474-80.

3. Simsek A, Kucuktopcu O, Ozgor F, Ozkuvanci U, Baykal M, Sarilar O, et al. Self and partner satisfaction rates after 3 part inflatable penile prosthesis implantation. Arch Ital Urol Androl. 2014 Sep 30;86(3):219-21.

4. Gentile G, Franceschelli A, Massenio P, Tuccio A, Cocci A, Divenuto L, et al. Patient's satisfaction after 2-piece inflatable penile prosthesis implantation: An Italian multicentric study. Arch Ital Urol Androl. 2016 Mar 31;88(1):1-3.

5. Smith JF, Walsh TJ, Conti SL, Turek P, Lue T. Risk factors for emotional and relationship problems in Peyronie's disease. J Sex Med. 2008 Sep;5(9): 2179-84.

6. Frey A, Sonksen J, Jakobsen H, Fode M. Prevalence and predicting factors for commonly neglected sexual side effects to radical prostatectomies: results from a cross-sectional questionnaire-based study. J Sex Med. 2014 Sep;11(9): 2318-26.

7. Sedigh O, Rolle L, Negro CL, Ceruti C, Timpano M, Galletto E, et al. Early insertion of inflatable prosthesis for intractable ischemic priapism: our experience and review of the literature. Int J Impot Res. 2011 Jul-Aug;23(4):158-64.

8. Morrison $\mathrm{T}$, Bearden A, Ellis S, Harriman R. Correlates of genital perceptions among Canadian post-secondary students. Electronic J Human Sexuality. 2005;8.

9. Shaeer O, Shaeer K. The Global Online Sexuality Survey (GOSS): erectile dysfunction among Arabic-speaking internet users in the Middle East. J Sex Med. 2011 Aug;8(8):215260-; quiz 60-3

10. Shaeer O, Shaeer K, Shaeer E. The Global Online Sexuality Survey (GOSS): female sexual dysfunction among Internet users in the reproductive age group in the Middle East. J Sex Med. 2012 Feb;9(2):411-24.

11. Wang R, Howard GE, Hoang A, Yuan JH, Lin HC, Dai YT. Prospective and long-term evaluation of erect penile length obtained with inflatable penile prosthesis to that induced by intracavernosal injection. Asian J Androl. 2009 Jul;11(4):411-5. 
12. Salem A, Shaeer O, Abdel-Aal A, Younes M. Comparative study of penile size before and after penile prosthesis implantation. Human Andrology. 2012; Vol. 2(Issue 2):p 42-4.

13. Deveci S, Martin D, Parker M, Mulhall JP. Penile length alterations following penile prosthesis surgery. Eur Urol. 2007 Apr;51(4):1128-31.

14. Hakky TS, Suber J, Henry G, Smith D, Bradley P, Martinez D, et al. Penile enhancement procedures with simultaneous penile prosthesis placement. Adv Urol. 2012;2012:314612.

15. Shaeer O. Supersizing the penis following penile prosthesis implantation. J Sex Med. 2010 Jul;7(7):2608-16.

16. Carrion R. Ventral phalloplasty. J Sex Med. 2010 Sep;7(9):2914-7.

17. Caso J, Keating M, Miranda-Sousa A, Carrion R. Ventral phalloplasty. Asian J Androl. 2008 Jan;10(1):155-7.

18. Shaeer O, Shaeer K. Dorsal Phalloplasty: Minimizing Shortening upon Penile Prosthesis Implantation by Tucking-in the Peno-Pubic Junction. VJPU. 2015;2(054). 